\title{
Video Endoscopic Inguinal Lymphadenectomy (VEIL) -a prospective critical perioperative assessment of feasibility and morbidity with points of technique in penile carcinoma
}

Harvinder Singh Pahwa ${ }^{1,3^{*}}$, Sanjeev Misra ${ }^{2}$, Awanish Kumar ${ }^{1}$, Vijay Kumar ${ }^{2}$, Akash Agarwal $^{2}$ and Rohit Srivastava ${ }^{1}$

\begin{abstract}
Background: Inguinal lymph node involvement is an important prognostic factor in penile cancer. Inguinal lymph node dissection allows staging and treatment of inguinal nodal disease. However, it causes morbidity and is associated with complications, such as lymphocele, skin loss and infection. Video Endoscopic Inguinal Lymphadenectomy (VEIL) is an endoscopic procedure, and it seems to be a new and attractive approach duplicating the standard open procedure with less morbidity. We present here a critical perioperative assessment with points of technique.

Methods: Ten patients with moderate to high grade penile carcinoma with clinically negative inguinal lymph nodes were subjected to elective VEIL. VEIL was done in standard surgical steps. Perioperative parameters were assessed that is - duration of the surgery, lymph-related complications, time until drain removal, lymph node yield, surgical emphysema and histopathological positivity of lymph nodes.

Results: Operative time for VEIL was 120 to180 minutes. Lymph node yield was 7 to 12 lymph nodes. No skin related complications were seen with VEIL. Lymph related complications, that is, lymphocele, were seen in only two patients. The suction drain was removed after four to eight days (mean 5.1). Overall morbidity was $20 \%$ with VEIL.

Conclusion: In our early experience, VEIL was a safe and feasible technique in patients with penile carcinoma with non palpable inguinal lymph nodes. It allows the removal of inguinal lymph nodes within the same limits as in conventional surgical dissection and potentially reduces surgical morbidity.
\end{abstract}

Keywords: Penile cancer, Inguinal lymphadenectomy, Video-assisted surgery, Video endoscopic inguinal lymphadenectomy (VEIL)

\section{Background}

Penile carcinoma is an important health problem in several developing countries, including India [1]. Inguinal lymph node involvement is an important cause of morbidity and an important predictive factor for survival in penile cancer patients [2-4]. In high risk patients, elective inguinal lymphadenectomy may offer survival advantage over watchful waiting $[5,6]$. Elective

\footnotetext{
* Correspondence: pahwakgmu@yahoo.co.in

'Department of Surgery, CSM Medical University (Formerly King George's

Medical University), Lucknow 226003, UP, India

${ }^{3}$ New Surgical Block, Department Of Surgery, C.S.M.U. (Erst. K.G.M.U.),

Lucknow 226005, UP, India

Full list of author information is available at the end of the article
}

inguinal lymphadenectomy is the standard of care for patients with larger tumour size, high histological grade and the presence of lymphovascular invasion $[1,6,7]$. Studies show that conventional inguinal lymph node dissection is associated with major complications such as lymphocele, skin loss and infection [8]. Some authors have described alternative procedures to reduce the morbidity of the treatment of inguinal lymph nodes, mainly by decreasing the area of dissection [9-11] but oncological results may not be as good as those with the radical procedure $[12,13]$.

An endoscopic procedure, with small incisions away from the dissecting area, seems to be a new and attractive 
approach, duplicating the standard open procedure with less morbidity [14]. We describe here points of technique and perioperative outcome with Video Endoscopic Inguinal Lymphadenectomy (VEIL) in patients with carcinoma of the penis.

\section{Methods}

Ten patients with locally advanced and/or high grade squamous cell carcinoma of the penis with no palpable inguinal lymph nodes suitable for elective inguinal lymph node dissection were enrolled in this study. The mean age of the patients was 51 years (range 39 to 62 years). The majority $(70 \%)$ of patients were at stage $\mathrm{T} 2$ while those at stages $\mathrm{T} 1$ and $\mathrm{T} 3$ were $20 \%$ and $10 \%$, respectively. In majority $(60 \%)$ of the patients, the tumor was moderately differentiated, whereas in $40 \%$, it was poorly differentiated. Partial penectomy was done in $70 \%$ of patients while $30 \%$ underwent total penectomy.

All patients underwent standard inguinal lymph node dissection, sparing the saphenous vein by VEIL. The techniques and surgical steps of VEIL are described below. The perioperative parameters assessed were the duration of surgery, lymph-related complications, time to drain removal, lymph node yield, surgical emphysema and histopathological positivity of lymph nodes.

\section{Consent}

Written informed consent was obtained from all the patients for publication of this report and any accompanying images.

\section{Surgical steps of VEIL}

We used the same technique as used for standard inguinal lymph node dissection.
The aim of this approach was to remove all of the lymph nodes that were at the most probable locations for first-line lymphatic invasion. Our technique for creation of space was based on the technique described by Tobias-Machado et al. [14].

1. Patient positioning-. After epidural block, the patient was positioned in the same way as in open inguinal lymph node dissection. The surgeon and assistant were positioned laterally to the patient's leg on the side of the operation and the video monitor system was placed at the opposite side next to the patient's waist.

2. Surface marking was done for the spermatic cord, inguinal ligament, anterior superior iliac spine, sapheno-femoral junction and femoral triangle (Figure 1).

3. Port placement-. A $12-\mathrm{mm}$ incision was made $4 \mathrm{~cm}$ distally to the lower vertex of the femoral triangle. Initially, scissors and dissecting forceps were used to develop a plane of dissection deep to the Scarpa's fascia. The second and third 5-mm ports were placed $6 \mathrm{~cm}$ superomedially and superolaterally to the apex of the triangle (Figure 2). Trocars were fixed with sutures. The first port accommodated a zero degree telescope.

4. Gas insufflation-. The working space was insufflated with $\mathrm{CO}_{2}$ at $12 \mathrm{mmHg}$ with quick space distension.

5. Retrograde dissection and identification of anatomical limits-. The dissection was carried out deep to the Scarpa's fascia and superiorly, up to the external oblique fascia, so that all superficial lymphatic tissue could be removed. The main landmarks of dissection were medially the adductor longus muscle, laterally - the sartorius muscle,

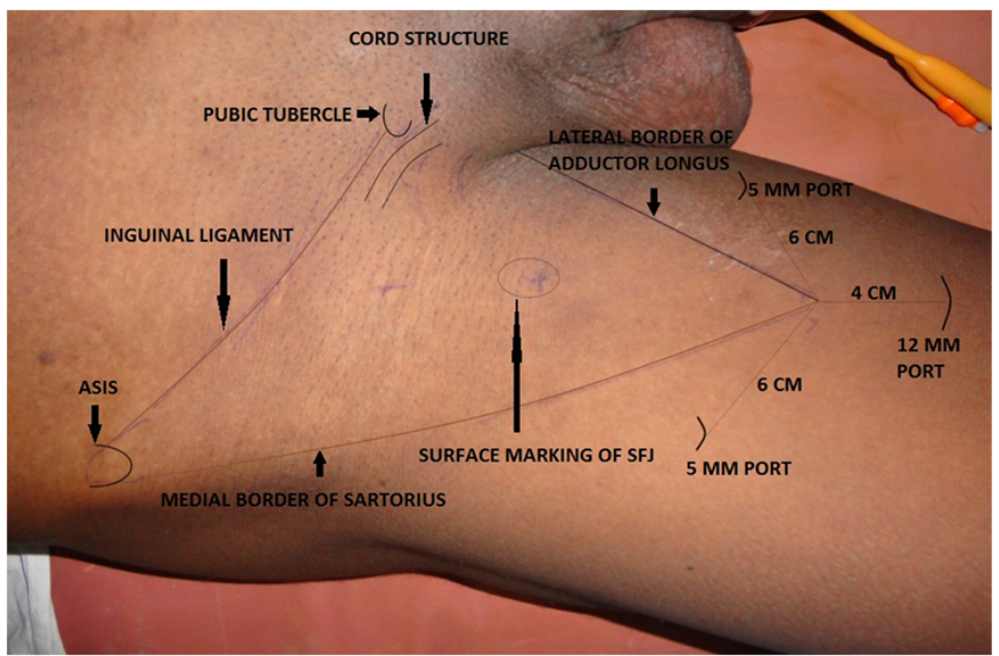

Figure 1 Surface marking showing important land marks. 


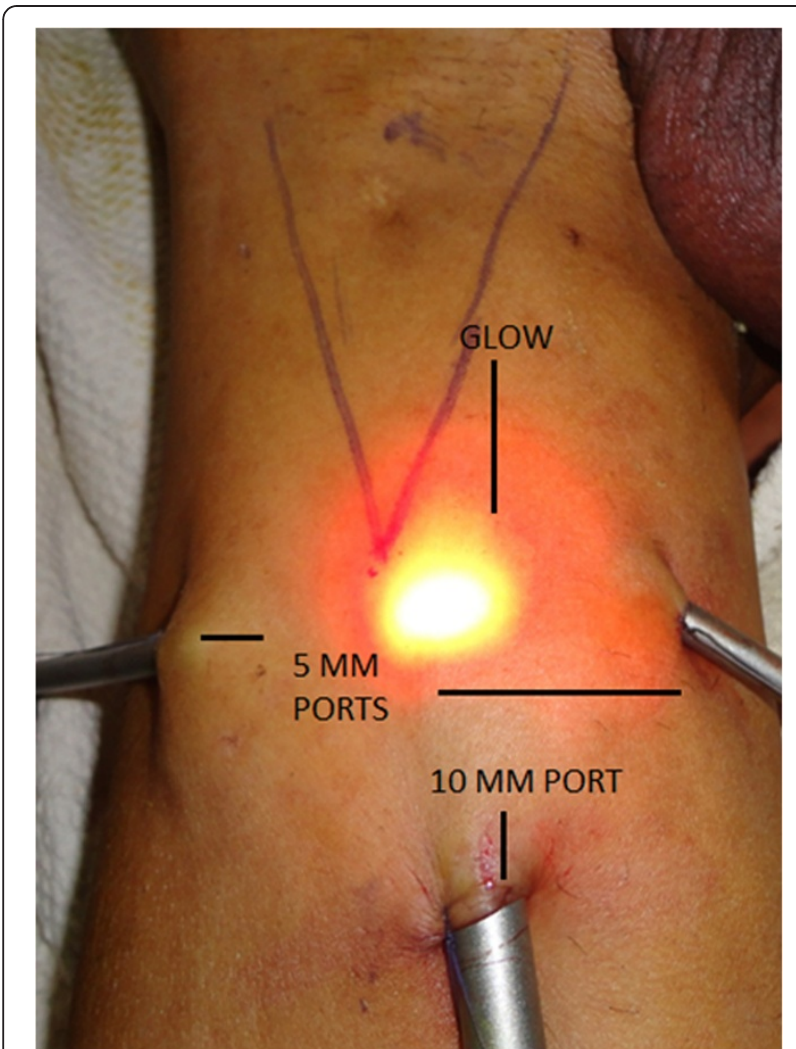

Figure 2 Port Placement and illuminated skin.

superiorly - the external oblique aponeurosis above the level of spermatic cord, and the inferior margin was the apex of the femoral triangle. Trans illumination, external pressure on skin and surface markings allow good orientation and monitoring of the progression of the dissection area towards the cavity (Figure 2).

6. Identification of landmarks-. The saphenous vein was identified medially and the spermatic cord and the external inguinal ring, superomedially. The branches of the femoral nerve, present laterally, were identified and preserved. The identified saphenous vein was dissected cranially up to the fossa ovalis.

7. The femoral artery was identified at the femoral triangle. At this point the muscular fascia was opened in all its extension.

8. Distal lymphatic tissue was coagulated with harmonic scalpel and cut at the vertex of the femoral triangle. Lymphatic tissue dissection was carried upwards along the saphenous vein till we reached the femoral vessels above the femoral ring.

9. Branches of the saphenous vein, namely, the superficial circumflex, superficial epigastric, superficial external pudendal, superficial lateral and medial cutaneous (Figure 3), were safely managed using harmonic and bipolar cautery and, as a result,

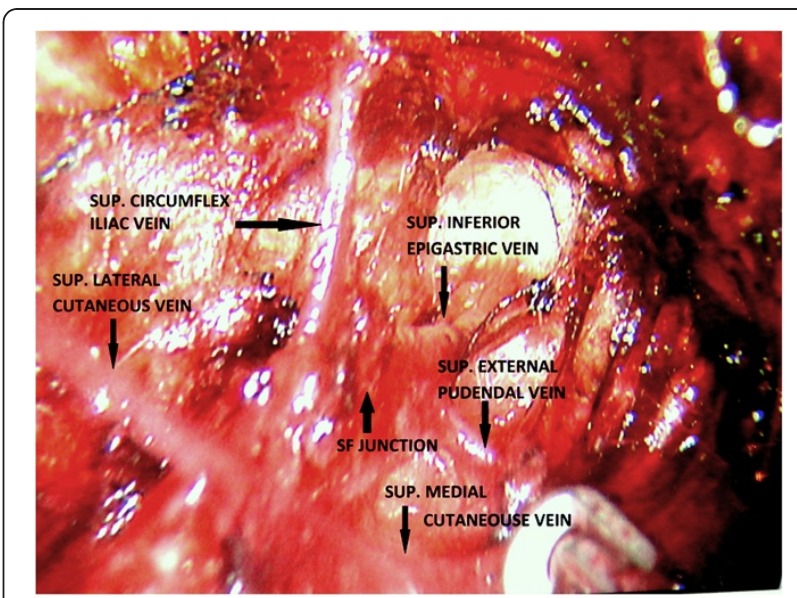

Figure 3 Saphenofemoral junction and Great saphenous vein with its tributaries.

no clips were used. Dissection of lympho-fatty tissue was completed (Figure 4).

10. A complete inguinal dissection was carried out as mentioned previously. Dissection ended by liberating the specimen consisting of fibrofatty tissue along with inguinal lymph nodes after coagulation of the proximal part of the lymphatic

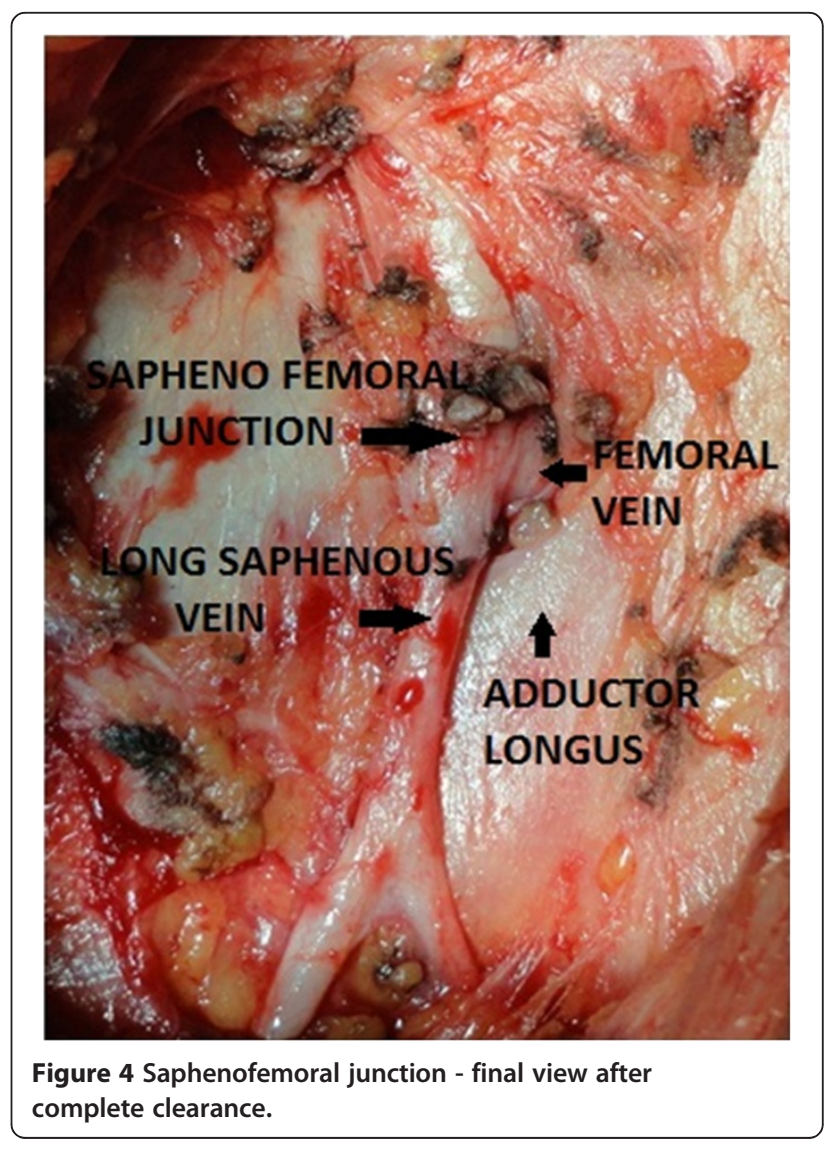


tissue with harmonic scalpel at the deep portion of the femoral channel.

11. The specimen having inguinal lymph nodes was removed via canula through the first 12 -mm port. If the specimen was larger the incision was increased and a larger canula or retrieval bag was used for removal of the specimen.

12. Port incisions were closed after placement of suction drainage through the lateral port.

13. An elastic compression bandage was applied from the lower part of leg to the thigh and early mobilization with lower limb physiotherapy was practiced. The drain was removed after four to eight days once drainage volume was less than $50 \mathrm{ml}$ in 24 hours.

\section{Results}

The intraoperative and postoperative period was uneventful in all the surgical patients. Operative time for VEIL was 120 to 180 minutes. Total operative time for VEIL was initially longer but was reduced subsequently (Table 1). No skin-related complications were seen. Lymph-related complication, a lymphocele, was seen in $2 / 10(20 \%)$ patients. This was managed by aspiration with a needle (single aspiration in one patient and two aspirations in the second patient). The suction drains were removed after four to eight days (mean 5.1 days). Lymph node yield was 7 to 12 lymph nodes. Self-resolving (one to three days) infra-umblical surgical emphysema was observed in all the patients. Only one patient had two positive lymph nodes on histopathology, so none of our patients required pelvic lymph node dissection. In our initial experience with VEIL, the overall morbidity was only $20 \%$. We present here our perioperative results, although we have had a short follow-up of 3 to 14 months.

\section{Discussion}

Inguinal lymph node involvement is present in approximately $30 \%$ of patients with clinically negative nodes and it is an important cause of morbidity and an important predictive factor for overall survival in penile cancer patients $[3,4]$. In high risk patients with penile cancers, studies have shown that elective inguinal lymphadenectomy offers better survival than salvage lymphadenectomy $[1,6,7]$. However, conventional inguinal lymph node dissection is associated with major complications, such as lymphocele, skin loss and infection [8]. As the morbidity associated with surgery is high, its role is being questioned, especially when the intention is prophylactic. Various techniques have been tried to reduce morbidity by reducing inguinal dissection templates $[9-11,15,16]$ or by doing sentinel lymph node biopsy with a radioisotope [17]. The VEIL technique was described by Tobias-Machado et al. in 2006 [14] with an aim to duplicate the standard radical procedure with less morbidity. By using VEIL, we were able to identify the same landmarks of the open surgery and perform a dissection following the same template of the radical surgery. We can see clearly through the endoscopic view if all lymphatic tissue within the limits of dissection has been removed at the end of the procedure as is the case in open surgery. We were able to perform complete inguinal lymph node dissection in all our patients with this technique. We have selected patients with clinically negative groins as this was our initial experience. This procedure has also been used for clinically positive inguinal nodes but has not been investigated in patients with bulky inguinal nodes. Pelvic lymph node dissection as it is only required if more than two nodes are positive on histopathology in clinically NO lymph nodes [18], so none of our cases required pelvic lymph node dissection.

Table 1 Perioperative outcome of patients with squamous cell carcinoma of the penis undergoing VEIL

\begin{tabular}{llllllll}
\hline $\begin{array}{l}\text { SN of } \\
\text { patients }\end{array}$ & $\begin{array}{l}\text { Duration of } \\
\text { surgery (in } \\
\text { minutes) }\end{array}$ & $\begin{array}{l}\text { Skin-related } \\
\text { complications }\end{array}$ & $\begin{array}{l}\text { Lymph- } \\
\text { related } \\
\text { complications }\end{array}$ & $\begin{array}{l}\text { Drain } \\
\text { removal } \\
\text { (in days) }\end{array}$ & $\begin{array}{l}\text { Lymph } \\
\text { node } \\
\text { yield }\end{array}$ & $\begin{array}{l}\text { Self-resolving infra- } \\
\text { umblical surgical } \\
\text { emphysema }\end{array}$ & $\begin{array}{l}\text { Histopathology of lymph nodes } \\
\text { (positive/negative for } \\
\text { malignancy) }\end{array}$ \\
\hline 1 & 170 & No & No & 5 & 8 & Positive & Negative \\
2 & 180 & No & No & 5 & 7 & Positive & Negative \\
3 & 175 & No & Lymphocele & 8 & 12 & Positive & Negative \\
4 & 160 & No & No & 6 & 11 & Positive & Negative \\
5 & 120 & No & No & 5 & 14 & Positive & Negative \\
6 & 130 & No & No & 5 & 10 & Positive & Positive (2) \\
7 & 140 & No & Lymphocele & 7 & 10 & Positive & Negative \\
8 & 120 & No & No & 7 & 12 & Positive & Negative \\
9 & 125 & No & No & 4 & 12 & Positive & Negative \\
10 & 120 & No & No & 4 & 10 & Positive & Negative \\
\hline
\end{tabular}


Complications with VEIL are fewer compared to an open surgical procedure, and this technique has the potential to reduce post-operative morbidity. The most important advantage of VEIL seems to be a decrease in skin events and, in our experience, there were no skin related complications. Tobias- Machado et al. reported 0\% cutaneous and $20 \%$ overall morbidity [19], whereas Sotelo et al. reported $23 \%$ lymphatic morbidity in their study [20]. Similar experience has been reported from other studies [14,21]. With VEIL the drains can be removed sooner and patients can be discharged earlier [10]. Operative time of VEIL was longer than with conventional open surgery, but the time decreased significantly as our experience with the procedure grew. As the incisions are small in VEIL, the results are more aesthetically pleasing. Master et al. [22] reported their experience with 25 groin dissections performed endoscopically. They performed complete inguinofemoral lymphadenectomy (Leg endoscopic groin lymphadenectomy - the LEG procedure) and stated that this procedure required operating time comparable to open procedures and carried less morbidity.

There are few reports in the literature of roboticassisted video endoscopic inguinal node dissection. The first such case was reported by Josephson et al. [23] in 2009. They performed endoscopic robotic-assisted inguinal lymph node dissection in a patient with penile cancer. Dogra et al. [24] published their experience with two cases of robotic-assisted inguinal node dissection in patients with carcinoma of the penis in 2011.

There may be apprehension regarding potential risk of tumor seeding due to infra-umbilical emphysema. Although there are no studies in this regard for video endoscopic inguinal lymph node dissection, there are studies evaluating the role of pneumoperitoneum in tumour seeding in laparoscopic surgeries. In human and animal studies, $\mathrm{CO} 2$ was not able to aerosolize large numbers of tumor cells using pressures of 8 to $15 \mathrm{mmHg}$ [25]. Further studies with long term follow-up are required to dispel the doubt regarding the role of infra-umbilical emphysema in tumur seeding.

New studies with a greater number of patients and long-term follow-up are needed to test the hypothesis that VEIL can retain the long-term oncological efficacy of the standard surgery and result in a lower morbidity. If this holds true, VEIL can become an attractive choice for the prophylactic inguinal lymphadenectomy in penile cancer patients. Other possible clinical indications for this new procedure may include prophylactic dissection for urethral and vulval cancers.

\section{Conclusion}

Our preliminary results show that video endoscopic inguinal lymphadenectomy is a safe and feasible technique in patients with penile carcinoma with no palpable lymph nodes. It allows the radical removal of inguinal lymph nodes within the same limits of conventional surgical dissection and potentially reduces surgical morbidity. VEIL has the potential to become the minimally invasive procedure for low volume inguinal lymph node disease and prophylactic inguinal lymph node dissection but long term studies with a greater number of patients are needed.

\section{Abbreviation}

VEIL: Video endoscopic inguinal lymphadenectomy.

\section{Competing interests}

All authors declare that they have no competing interests.

\section{Authors' contributions}

HSP was the operating surgeon and made substantive intellectual contributions in this study, including acquisition of data, interpretation and drafting/editing of the manuscript, and has given final approval of the version to be published. SM has given substantive intellectual contributions in this study and helped in the interpretation and drafting/editing of the manuscript, and has given final approval of the version to be published. AK, $\mathrm{VK}, \mathrm{AA}$, and RS made substantive contributions to this study, including acquisition of data, interpretation and drafting/editing of the manuscript, and have given final approval of the version to be published. All authors read and approved the final manuscript.

\section{Author details}

${ }^{1}$ Department of Surgery, CSM Medical University (Formerly King George's Medical University), Lucknow 226003, UP, India. ${ }^{2}$ Department of Surgical Oncology, CSM Medical University (Formerly King George's Medical University), Lucknow 226003, UP, India. ${ }^{3}$ New Surgical Block, Department Of Surgery, C.S.M.U. (Erst. K.G.M.U.), Lucknow 226005, UP, India.

Received: 31 July 2013 Accepted: 12 February 2013

Published: 22 February 2013

\section{References}

1. Misra S, Chaturvedi A, Misra NC: Penile carcinoma: a challenge for the developing world. Lancet Oncol 2004, 5:240-247.

2. Srinivas V, Morse MJ, Herr HW Sogani PC, Whitmore WF Jr: Penile cancer: Relation of extent of nodal metastasis to survival. J Urol 1987, 137:880-882.

3. Ficarra V, Zattoni F, Cunico SC, Galetti TP, Luciani L, Fandella A, Guazzieri S, Maruzzi D, Sava T, Siracusano S, Pilloni S, Tasca A, Martignoni G, Gardiman M, Tardanico R, Zambolin T, Cisternino A, Artibani W, GruppoUroOncologico del Nord Est (Northeast Uro-Oncological Group) Penile Cancer Project: Lymphatic and vascular embolizations are independent predictive variables of inguinal lymph node involvement in patients with squamous cell carcinoma of the penis: Gruppo Uro-Oncologico del Nord Est (Northeast Uro-Oncological Group) Penile Cancer data base data. Cancer 2005, 103:2507-2516.

4. Ornellas AA, Seixas AL, Marota A, Wisnescky A, Campos F, de Moraes JR: Surgical treatment of invasive squamous cell carcinoma of the penis: retrospective analysis of 350 cases. J Urol 1994, 151:1244-1249.

5. Kroon BK, Horenblas S, Lont AP, Tanis PJ, Gallee MP, Nieweg OE: Patients with penile carcinoma benefit from immediate resection of clinically occult lymph node metastases. J Urol 2005, 173:816-819.

6. Marqulis V, Saqalowsky Al: Penile cancer: management of regional lymphatic drainage. Urol Clin North Am 2010, 37:411-419.

7. Slaton JW, Morgenstern N, Levy DA, Santos MW Jr, Tamboli P, Ro JY, Ayala AG, Pettaway CA: Tumor stage, vascular invasion and the percentage of poorly differentiated cancer: independent prognosticators for inguinal lymph node metastasis in penile squamous cancer. J Urol 2001, 165:1138-1142.

8. Ravi R: Correlation between the extent of nodal involvement and survival following groin dissection for carcoinoma of the penis. Brit J Urol 1993, 72:817-819. 
9. Catalona WJ: Modified inguinal lymphadenectomy for carcinoma of the penis with preservation of saphenous veins: technique and preliminary results. J Urol 1988, 140:306-310.

10. d'Ancona CA, de Lucena RG, Querne FA, Martins MH, Denardi F, Netto NR $\mathrm{Jr}$ : Long-term followup of penile carcinoma treated with penectomy and bilateral modified inguinal lymphadenectomy. J Urol 2004, 172:498-501. discussion 501.

11. Lont AP, Horenblas S, Tanis PJ, Gallee MP, van Tinteren H, Nieweg OE: Management of clinically node negative penile carcinoma: improved survival after the introduction of dynamic sentinel node biopsy. J Urol 2003, 170:783-786.

12. Lopes A, Rossi BM, Fonseca FP, Morini S: Unreliability of modified inguinal lymphadenectomy for clinical staging of penile carcinoma. Cancer 1996, 77:2099-2102.

13. Kroon BK, Lont AP, Valdés Olmos RA, Nieweg OE, Horenblas S: Morbidity of dynamic sentinel node biopsy in penile carcinoma. J Urol 2005, 173:813-815.

14. Tobias-Machado M, Alessandro T, Molina WR Jr, Forseto PH Jr, Juliano RV, Wroclawski ER: Video Endoscopic Inguinal Lymphadenectomy (VEIL): Minimally Invasive Resection of Inguinal Lymph Nodes. Int Braz I Urol 2006, 32:316-321.

15. Parra RO: Accurate staging of carcinoma of the penis in men with nonpalpable inguinal lymph nodes by modified inguinal lymphadenectomy. J Urol 1996, 155:560-563.

16. Colberg JW, Andriole GL, Catalona WJ, et al: Long-term follow-up of men undergoing modified inguinal lymphadenectomy for carcinoma of the penis. Br J Urol 1997, 79:54-57.

17. Joost A.P. Leijte, Bin K. Kroon, Valdés Olmos RA, Nieweg OE, Horenblas S: Reliability and Safety of Current Dynamic Sentinel Node Biopsy for Penile Carcinoma. Eur Urol 2007, 52:170-177.

18. Protzel C, Alcaraz A, Horenblas S, Pizzocaro G, Zlotta A, Hakenberg OW: Lymphadenectomy in the surgical management of penile cancer. Eur Urol 2009, 55:1075-1088.

19. Tobias-Machado M, Tavares A, Ornellas AA, Molina WR Jr, Juliano RV, Wroclawski ER: Video endoscopic inguinal lymphadenectomy: a new minimally invasive procedure for radical management of inguinal nodes in patients with penile squamous cell carcinoma. J Urol 2007, 177:953-957.

20. Sotelo R, Sánchez-Salas R, Carmona O, Garcia A, Mariano M, Neiva G, Trujillo G, Novoa J, Cornejo F, Finelli A: Endoscopic Lymphadenectomy for Penile Carcinoma. J Endourol 2007, 21:364-367.

21. Sotelo R, Sánchez-Salas R, Clavijo R: Endoscopic inguinal lymph node dissection for penile carcinoma: the developing of a novel technique. World J Urol 2009, 27:213-219.

22. Master V, Ogan K, Kooby D. Hsiao W, Delman K: Leg Endoscopic Groin Lymphadenectomy (LEG Procedure): Step-by-Step Approach to a straightforward Technique. Eur Urol 2009, 56(5):821-828.

23. Josephson DY, Jacobsohn KM, Link BA, Wilson TG: Robotic-assisted endoscopic inguinal lymphadenectomy. Urology 2009, 73(1):167-170.

24. Dogra PN, Saini AK, Singh P: Robotic-assisted inguinal lymph node dissection: a preliminary report. Indian J Urol 2011, 27(3):424-427.

25. Reymond MA, Schneider C, Hohenberger W, Köckerling F: The pneumoperitoneum and its role in tumor seeding. Dig Surg 1998, 15(2):105-9.

\section{Submit your next manuscript to BioMed Central and take full advantage of:}

- Convenient online submission

- Thorough peer review

- No space constraints or color figure charges

- Immediate publication on acceptance

- Inclusion in PubMed, CAS, Scopus and Google Scholar

- Research which is freely available for redistribution

Submit your manuscript at www.biomedcentral.com/submit 